\title{
Nanoparticle albumin-bound (nab)-paclitaxel for the treatment of pancreas ductal adenocarcinoma
}

This article was published in the following Dove Press journal:

Gastrointestinal Cancer: Targets and Therapy

6 January 2015

Number of times this article has been viewed

\author{
Vignesh Narayanan' \\ Colin D Weekes ${ }^{1,2}$ \\ 'Division of Medical Oncology, \\ Department of Medicine, \\ ${ }^{2}$ Developmental Therapeutics \\ Program, University of Colorado \\ Cancer Center, University of \\ Colorado School of Medicine, \\ Aurora, CO, USA
}

Correspondence: Colin D Weekes University of Colorado Cancer Center, I280| E 17th Avenue, Aurora, CO 80045, USA

Email colin.weekes@ucdenver.edu

\begin{abstract}
Pancreatic adenocarcinoma is a leading cause of cancer-related mortality worldwide, and surgical resection offers the only chance of cure. Since the majority of patients have unresectable disease at presentation, the emphasis has been on identifying effective chemotherapy regimens to prolong survival and control tumor burden. Gemcitabine has been the cornerstone of treatment ever since it was discovered to be an active agent in advanced pancreatic cancer nearly two decades ago, but the overall prognosis in patients with metastatic disease remains dismal. A dense fibrotic stroma around the tumor devoid of vasculature and the resultant hypoxic tumor microenvironment are implicated in the chemotherapy-resistant nature of this malignancy. In recent years, a growing body of literature has further elucidated several aspects of pancreatic tumor biology, such as its ability to utilize albumin from the peritumoral tissues to support its metabolic needs. High-pressure homogenization of paclitaxel with nanoparticle albumin results in the formation of soluble $130 \mathrm{~nm}$ complexes with albumin acting as the carrier for the otherwise hydrophobic paclitaxel. Once these complexes reach the tumor milieu, they act by depleting the tumor stroma. In addition, paclitaxel is also transported into the tumor cell along with albumin, where it then exerts its antineoplastic activity. Nanoparticle albuminbound (nab)-paclitaxel also increases gemcitabine levels inside the tumor cells by inhibiting cytidine deaminase, the enzyme that degrades gemcitabine. This review focuses on proposed mechanisms of efficacy of nab-paclitaxel in pancreatic cancer and discusses the preclinical and clinical studies of relevance.
\end{abstract}

Keywords: pancreatic adenocarcinoma, nab-paclitaxel, gemcitabine, SPARC, tumor stroma

\section{Introduction}

The treatment of exocrine pancreatic ductal adenocarcinoma (PDA) poses a tremendous therapeutic challenge to the oncology community. In the USA and other developed countries, pancreatic cancer constitutes less than $3 \%$ of new cancers diagnosed each year, yet the mortality associated with it is inexorably high. ${ }^{1-4}$ Among gastrointestinal malignancies in the USA, the annual incidence of pancreatic cancer is much lower than that of colorectal cancer (46,420 versus 136,830 estimated new cases per year, respectively). However, the mortality ensuing from pancreatic cancer is second only to colorectal cancers (39,590 versus 50,310 estimated deaths per year, respectively), and almost all patients with pancreatic cancer are likely to die from it. ${ }^{1}$ The incidence of pancreatic cancer is also projected to increase in the years to come, and it is ominously predicted to surpass breast, prostate, and colon cancer to become the second leading cause of cancer-related mortality by the year $2030 .^{5}$

Several factors contribute to the lethality of pancreatic cancer (Table 1). Due to the nonspecific nature of heralding symptoms and the lack of biomarkers to identify 
Table I Factors implicated in high mortality of pancreatic adenocarcinoma

\begin{tabular}{|c|c|}
\hline \multirow[t]{3}{*}{ Patient factors } & Nonspecific symptoms \\
\hline & Advanced age, comorbidity (DM, VTE) \\
\hline & Unresectable stage at presentation \\
\hline \multirow[t]{2}{*}{ Ineffective screening } & Paucity of biomarkers to identify patients at risk \\
\hline & Expensive and invasive modalities (MRI, EUS) \\
\hline Tumor & Desmoplastic tumor stroma \\
\hline microenvironment & Relatively avascular and hypoxic tumor milieu \\
\hline \multirow[t]{3}{*}{ Treatment } & Toxicity of multiagent chemotherapy \\
\hline & Complex radiation field, radiation resistance \\
\hline & Genetic heterogeneity \\
\hline
\end{tabular}

Abbreviations: DM, diabetes mellitus; VTE, venous thromboembolism; MRI, magnetic resonance imaging; EUS, endoscopic ultrasound.

patients at risk, most patients present with locally advanced or metastatic disease. PDA tumors are characterized by a notoriously intense fibrotic or "desmoplastic" reaction surrounding the tumor cells that contributes to increased extracellular fluid pressure, resulting in collapse of blood vessels in the tumor stroma. ${ }^{6}$ The resultant hypoxic peritumoral milieu is thus a significant impediment to the effective delivery of chemotherapy to the tumor. ${ }^{7}$ Based on genomic analyses of pancreatic tumors by next-generation sequencing, PDAs have been found to exhibit a wide array of genetic abnormalities and core signaling abnormalities that enhance tumorigenesis. ${ }^{8}$ Remarkable variations in genetic abnormalities in individual tumors have also been described and this heterogeneity adds complexity to the utilization of molecularly targeted therapeutics. ${ }^{8}$ Even though patients with early-stage disease undergo curative intent treatment by surgical resection followed by adjuvant therapy, nearly $80 \%$ relapse, and eventually succumb to this recalcitrant malignancy. ${ }^{9-11}$ Historically, the prognosis of patients with metastatic disease is even more dismal, as less than half of patients will survive beyond one year with therapy. ${ }^{12,13}$

Since most PDAs are unresectable at presentation, the onus has been on chemotherapy regimens to control tumor burden, reduce symptoms, and prolong overall survival (OS). However, in the past two decades, impactful therapeutic regimens have been few and far between. In the late 1990s, gemcitabine emerged as an effective treatment option based on the results of a sentinel study. ${ }^{14}$ When compared with 5-fluorouracil, the clinical benefit response with gemcitabine was higher ( $5 \%$ versus $24 \%, P=0.002$ ), and it also prolonged OS by 1.2 months $(4.4 \%$ versus 5.6 months, $P=0.002) .{ }^{14}$ Since then, several combination chemotherapy regimens using a gemcitabine backbone have been studied, but despite improved overall response rates (ORR), none have resulted in meaningful prolongation of OS in advanced disease. ${ }^{15-19}$
Erlotinib, a tyrosine kinase inhibitor directed against the human epidermal growth factor receptor, garnered great interest in the realm of molecularly targeted antineoplastic therapy for metastatic PDA. ${ }^{20}$ In a pivotal trial, the addition of erlotinib to gemcitabine resulted in a survival advantage compared with gemcitabine alone (hazard ratio [HR] for death 0.82 ; 95\% confidence interval [CI] $0.69-0.99, P=0.04$ ), but the OS was prolonged by a mere 2 weeks, a result that is uniformly perceived as not clinically meaningful. ${ }^{20}$ More recently, the results from a study group in France confirmed the superiority of the combination regimen of 5-fluorouracil, oxaliplatin, and irinotecan (FOLFIRINOX) over gemcitabine monotherapy in yet another landmark trial. ${ }^{21}$ When compared with single-agent gemcitabine, this combination regimen confers a median survival advantage of 4.3 months (HR for death 0.57 ; 95\% CI $0.45-0.73, P<0.001)$ and a progression-free survival (PFS) improvement of 3.1 months (HR for disease progression 0.47 ; 95\% CI $0.37-0.59, P<0.001) .{ }^{21}$ However, patients with metastatic disease and good performance status were rigorously selected and patients with carcinoma of the head of the pancreas constituted less than $40 \%$ of the study population. Moreover, a significantly higher proportion of patients experienced grade 3 or 4 neutropenia, febrile neutropenia, thrombocytopenia, fatigue, sensory neuropathy, and diarrhea. Thus, the toxicity profile of this regimen significantly limits its applicability to a large proportion of PDA patients, namely the elderly and those with poor performance status.

Currently, the therapeutic landscape of pancreatic adenocarcinoma is in an exciting phase owing to research that has better defined the molecular mechanisms of PDA oncogenesis and maintenance, although implementing this information in the clinical setting has not been feasible thus far. However, recent studies have shown that altering the PDA stroma by specifically targeting the extracellular matrix holds promise. ${ }^{22-24}$ This review focuses on the novel mechanistic effects of nanoparticle albumin-bound (nab)-paclitaxel on the tumor stroma as well as its preclinical pharmacology and clinical utility in the treatment of patients with PDA.

\section{Solvent-based paclitaxel}

Paclitaxel was first isolated from the bark of Taxus brevifolia, also known as the Pacific yew tree, found in North America. ${ }^{25}$ The potent antineoplastic activity of paclitaxel is attributed to its ability to disrupt microtubule assembly, resulting in death of cancer cells by mitotic catastrophe. ${ }^{26}$ During the initial stages of drug development, the insolubility of paclitaxel in aqueous medium was a major hurdle in ensuring effective drug delivery. The use of polyethoxylated castor 
oil (Cremophor EL ${ }^{\circledR}$, BASF Corporation, Ludwigshafen, Germany) as a solvent mitigated this issue by rendering paclitaxel more soluble, but this strategy is associated with several limitations. Cremophor is implicated in the notorious propensity of paclitaxel to cause infusional hypersensitivity reactions, which tend to be severe in up to $10 \%$ of patients who receive it, therefore necessitating premedication with steroids and antihistamines. ${ }^{27,28}$ Hepatotoxicity is a feared complication attributed to the corrosive effects of Cremophor on plasticizers in standard intravenous infusion tubes, and hence requires special polyvinyl chloride-free tubing with an in-line filter. ${ }^{29}$ Importantly, Cremophor causes entrapment of paclitaxel in large micelles, which decreases bioavailability, resulting in impaired efficacy. ${ }^{30}$ In addition, sequestration of paclitaxel in micelles leads to nonlinear pharmacokinetics and decreased clearance of the drug, which increases systemic exposure and toxicity. ${ }^{31}$ Paclitaxel-induced peripheral neuropathy may be severe, irreversible, and dose-limiting, and Cremophor is purported to play a role because it can cause axonal degeneration and demyelination. ${ }^{32}$

Although solvent-based paclitaxel is an active agent in combating many different malignancies, its efficacy in patients with PDA has been disappointing. In clinical studies, single-agent paclitaxel in unresectable PDA induces an ORR of less than $10 \%$, without any improvement in PFS or OS. ${ }^{33,34}$ Similarly poor results have also been seen with paclitaxel in gemcitabine-refractory disease. ${ }^{35,36}$ The use of docetaxel likewise demonstrated limited clinical efficacy in PDA patients. ${ }^{37-39}$

\section{Nanotechnology in creation of nab-paclitaxel}

Particles between the sizes of 1 and 1,000 nanometers (nm) are called nanoparticles. A high surface to volume ratio augments their interaction with other molecules, and allows for tremendous versatility in enhancing drug delivery across difficult biological barriers, such as the blood-brain and blood-tumor barriers. ${ }^{40}$ Another prime advantage of nanotechnology is in rendering hydrophobic molecules such as paclitaxel soluble in aqueous media by enveloping it in albumin nanoparticles. ${ }^{40}$ When human serum albumin at a concentration of $3 \%-4 \%$, akin to its natural concentration in blood, is mixed with paclitaxel in an aqueous solvent and passed through a jet under high pressure, it results in the conjugation of albumin with paclitaxel and leads to the formation of spherical nanoparticles with a mean diameter of $130 \mathrm{~nm} .{ }^{41}$ Paclitaxel forms the center of the nanoparticle that is covered by a thin outer layer of albumin. ${ }^{40}$ The inherent negative surface charge of albumin and its solubility in aqueous media prevents agglomeration of the nanoparticles and confers stability in suspension. ${ }^{40}$ Due to the noncovalent binding of paclitaxel with albumin through hydrophobic interaction, the complexes dissociate rapidly after intravenous infusion to aid rapid tissue distribution. ${ }^{40}$

Nab-paclitaxel (Abraxane ${ }^{\circledR}$, Celgene Inc., Odenton, MD, USA) has several advantages compared with Cremophorbased paclitaxel (Table 2), and first received US Food and Drug Administration approval based on its efficacy in the treatment of refractory metastatic breast cancer in $2005 .{ }^{42}$ It is also currently approved for the treatment of metastatic non-small-cell lung cancer and recently received approval for the treatment of metastatic PDA in September 2013. ${ }^{42}$

\section{Preclinical evidence}

Several preclinical studies have shed light on the biological basis for the efficacy of nab-paclitaxel in pancreatic cancer (Table 3).

\section{Interactions of nab-paclitaxel with albondin (gp60) and caveolin}

Utilization of certain physiological attributes of albumin, such as its ubiquity in plasma and activity as a transport protein, ensures an effective mechanism for delivery of paclitaxel. The strong binding affinity between human serum albumin and paclitaxel is an added advantage that provides enhanced stability to the nab-paclitaxel formulation. ${ }^{43}$ Each $50 \mathrm{~mL}$ vial contains $100 \mathrm{mg}$ of nab-paclitaxel and $900 \mathrm{mg}$ of human albumin, and upon reconstitution with $20 \mathrm{~mL}$ of $0.9 \%$ sodium chloride, each $\mathrm{mL}$ of suspension contains $5 \mathrm{mg}$ of nab-paclitaxel. ${ }^{44}$ After intravenous infusion, the nanoparticles dissociate into individual soluble albumin-paclitaxel complexes, which then bind to the albumin receptor called albondin or glycoprotein 60 (gp60). ${ }^{45}$ Transmembrane scaffolding proteins belonging to the caveolin family then mediate transcytosis of nab-paclitaxel across the endothelial cell into the peritumor interstitium. ${ }^{46,47}$ Due to the specific

Table 2 Differences between solvent-based paclitaxel and nabpaclitaxel

\begin{tabular}{lll}
\hline & SB-paclitaxel & Nab-paclitaxel \\
\hline Solvent & Castor oil-based & Solvent-free \\
Pharmacokinetics & Nonlinear & Linear \\
Hypersensitivity & Common & None \\
Premedication & Steroids, antihistamines & Not required \\
Special infusion tubing & Required & Not required \\
Infusion time & 3 hours & 30 minutes \\
\hline
\end{tabular}

Abbreviation: SB, solvent-based. 
Table 3 Proposed mechanisms for efficacy of nab-paclitaxel in pancreatic cancer in preclinical studies

\begin{tabular}{|c|c|c|}
\hline Barrier & $\begin{array}{l}\text { Proposed MOA } \\
\text { of nab-paclitaxel }\end{array}$ & Effect \\
\hline $\begin{array}{l}\text { Impaired drug } \\
\text { delivery }\end{array}$ & $\begin{array}{l}\text { Transcytosis by gp } 60 \text {, } \\
\text { caveolin } \\
\text { Endocytosis by SPARC }\end{array}$ & $\begin{array}{l}\text { Peritumoral drug delivery } \\
\text { Intratumoral drug } \\
\text { delivery }\end{array}$ \\
\hline $\begin{array}{l}\text { Desmoplastic } \\
\text { stroma }\end{array}$ & Stromal depletion & Impaired tumor defense \\
\hline $\begin{array}{l}\text { Macropinocytosis } \\
\text { of albumin }\end{array}$ & $\begin{array}{l}\text { Engulfment of albumin- } \\
\text { bound paclitaxel }\end{array}$ & $\begin{array}{l}\text { Intratumoral drug } \\
\text { delivery }\end{array}$ \\
\hline $\begin{array}{l}\text { Gemcitabine } \\
\text { resistance }\end{array}$ & $\begin{array}{l}\text { Cytidine deaminase } \\
\text { inhibition }\end{array}$ & $\begin{array}{l}\text { Increased intratumoral } \\
\text { gemcitabine }\end{array}$ \\
\hline
\end{tabular}

Abbreviations: MOA, mechanism of action; gP60, glycoprotein 60; SPARC, secreted protein, acidic and rich in cysteine.

interaction between albumin, gp60 and activation of caveolin, a higher concentration of drug is delivered to the tumor when compared with Cremophor-paclitaxel. In preclinical studies using xenograft models, a ten-fold increase in endothelial cell binding and a four-fold increase in transcytosis were observed with nab-paclitaxel when compared with Cremophor-paclitaxel. ${ }^{48}$ Further, in this study, Cremophor inhibited caveolar transport, thus explaining its inferiority in achieving drug delivery into tumor cells. ${ }^{48}$ Since PDA cells depend on albumin for their metabolic needs, paclitaxel is taken up into the tumor cells by virtue of being bound to albumin nanoparticles and subsequently exerts its antineoplastic activity. ${ }^{49,50}$

\section{Role of SPARC}

Secreted protein acidic and rich in cysteine (SPARC) is a matrix glycoprotein with varied functions, such as angiogenesis, cell proliferation, cell differentiation, and cell migration, as well as tissue remodeling and wound repair. ${ }^{51}$ It is expressed in normal tissues where it serves as a marker of activated fibroblasts. ${ }^{52}$ It is also overexpressed in multiple malignancies, although its exact role in tumorigenesis is not clearly understood. ${ }^{53}$ Despite loss of expression of SPARC in pancreatic cancer cells, the fibroblasts around the tumor continue to express SPARC, where it is proposed to aid metastasis. ${ }^{51}$ Gene expression analyses have also established SPARC as a crucial driver of the invasiveness of pancreatic cancer. $^{54}$

Infante et al investigated the prognostic significance of SPARC expression in PDA cells and in the tumor stroma in a cohort of 299 patients who underwent pancreaticoduodenectomy at Johns Hopkins Hospital over a period of 5.5 years between 1998 and 2003. ${ }^{53}$ Patients whose pancreatic cancer stromal fibroblasts (but not PDA cells) expressed
SPARC fared significantly worse compared with patients whose tumor stroma did not express SPARC (median survival 15 months versus 30 months, respectively; log rank $P<0.001)$. This prognostic information laid the platform for recent studies that have investigated the relationship between nab-paclitaxel and overexpression of SPARC in PDA. As part of the Phase I/II study of gemcitabine plus nab-paclitaxel in advanced PDA, Von Hoff et al evaluated the SPARC status of 36 patients and classified them into high-SPARC and low-SPARC groups. ${ }^{55}$ The OS of patients with high SPARC expression was significantly better than the low-SPARC group (median OS 18 months versus 8 months, $P=0.043$ ), suggesting stromal SPARC as a potential target of nab-paclitaxel. After entry of nab-paclitaxel into the peritumoral interstitium from the vascular endothelium through the previously discussed albumin-gp60-caveolin pathway, SPARC is proposed to facilitate the transfer of drug into the tumor cells. ${ }^{55}$ However, the role of SPARC in facilitating delivery of nab-paclitaxel is debatable based on the results of two recent reports. First, Neesse et al demonstrated in a genetically engineered mouse model devoid of SPARC that the effect of murine nab-paclitaxel was dose-dependent and thus independent of SPARC expression. ${ }^{56}$ Second, analyses of SPARC expression in the pivotal Phase III MPACT study were recently presented as an oral abstract at the European Society of Medical Oncology ${ }^{57}$ Contrary to the results of the Phase I/II study, expression of SPARC was not associated with OS, but the final results are yet to be published. Thus, the role of SPARC in delivery of nab-paclitaxel might not be as important as previously thought.

\section{Depletion of tumor stroma}

The milieu around PDA consists of both matrix proteins such as collagen, hyaluronic acid, and the aforementioned SPARC, as well as a mixture of cancer-associated fibroblasts and endothelial and inflammatory cells..${ }^{6,7}$ Depletion of this tumor stroma and curtailing the desmoplastic reaction is therefore considered a crucial strategy in stopping the growth of PDA. ${ }^{6}$

In a small but novel study, Alvarez et al administered nab-paclitaxel and gemcitabine to 16 patients in a neoadjuvant fashion and determined the effects of this combination regimen on the tumor stroma by endoscopic ultrasound elastography and examination of surgically resected tumor specimens. ${ }^{58}$ Not only was there a significant decrease in tumor stiffness on endoscopic ultrasound elastography, but there was also a decrease in cancer-associated fibroblasts and significant disruption of the intense collagen architecture 
among patients treated with this regimen. Similarly, stromal disruption was noted in patient-derived xenograft mouse models treated with nab-paclitaxel and gemcitabine in the study by Von Hoff et $\mathrm{al}^{55}$ In their study, genetically engineered mice bearing tumors received nab-paclitaxel, gemcitabine, or a combination of these two agents. Although similar responses were observed in mice treated with nab-paclitaxel, an increase in collagen and cancer-associated fibroblasts was documented in the gemcitabine-only group. Thus, stromal disruption is an exclusive effect of nab-paclitaxel. In addition, the intratumoral concentration of gemcitabine was nearly 3 -fold higher in mice treated with nab-paclitaxel plus gemcitabine than in those receiving gemcitabine alone. The exact mechanism of action of nab-paclitaxel in depleting the tumor stroma has not been elucidated, but could be mediated by SPARC. ${ }^{55}$

\section{Oncogenic K-ras and macropinocytosis}

Upwards of $95 \%$ of PDA tumors possess activating mutations of the Kras oncogene, most commonly at the G12 residue. ${ }^{59}$ Kras activating mutations are also early inciting events in pancreatic malignancies, and mutations are found in every stage in the continuum from pancreatic intraepithelial neoplasia to overt adenocarcinoma. ${ }^{60}$ Despite intensive efforts, direct pharmacological inhibition of Kras has been unsuccessful. ${ }^{61}$ Hence, inhibiting downstream pathways and Kras-mediated mechanisms of tumor survival have been pursued with varying degrees of success. ${ }^{61}$ Macropinocytosis is one such mechanism of tumor survival, wherein extracellular fluid proteins are internalized by the formation of large vesicles known as macropinosomes. ${ }^{62}$ This process constitutes an important route of nutrient uptake in PDA. Commisso et al demonstrated that Ras-transformed cells induce macropinocytosis in PDA cell lines. ${ }^{50}$ Compared with PDA cell lines with wild-type Kras, cell lines with homozygous Kras activating mutations display higher tetramethylrhodamine-dextran (a marker for macropinocytosis). In addition, knockdown of Kras results in macropinocytosis being shut off. ${ }^{50}$ Since two-thirds of extracellular fluid consists of plasma proteins and because albumin is the most abundant plasma protein, it is conceivable that by virtue of binding albumin with paclitaxel, macropinocytosis might result in enhanced uptake of paclitaxel, akin to a Trojan-horse phenomenon. ${ }^{63}$ However, this hypothesis is yet to be proven in clinical studies.

\section{Potentiation of the effect of gemcitabine}

In a genetically engineered mouse model of pancreatic cancer, administration of gemcitabine in combination with nab-paclitaxel prevented the growth of tumors in some mice and even resulted in regression of tumor in others. ${ }^{64}$ However, when gemcitabine was administered as a single agent, the tumors more than doubled in size, and although nab-paclitaxel monotherapy had some antitumor activity, none of the tumors regressed. ${ }^{64}$ The authors discovered that intratumoral levels of gemcitabine were higher when administered with nab-paclitaxel. This synergy is due to the inhibition of the gemcitabine-metabolizing enzyme, cytidine deaminase, by paclitaxel-induced formation of reactive oxygen species. This eventually results in enhanced stability of gemcitabine as well. ${ }^{64}$

\section{Clinical evidence}

\section{Phase I/II}

The combination of nab-paclitaxel and gemcitabine in the first-line treatment of metastatic pancreatic cancer was studied in a multicenter, open-label Phase I/II trial. ${ }^{55}$ In the Phase I portion, the primary aim was to identify the maximum tolerated dose and dose-limiting toxicities of gemcitabine at a dose of $1,000 \mathrm{mg} / \mathrm{m}^{2}$ followed by nab-paclitaxel at a dose of 100,125 , or $150 \mathrm{mg} / \mathrm{m}^{2}$, given intravenously on days 1,8 , and 15 every 28 days, using a standard $3+3$ Phase I doseescalation design. Accrual was continued at the maximum tolerated dose in the Phase II portion of the study to determine the safety and efficacy of the combination in addition to the decline in CA19-9 levels and positron emission tomography scan response with treatment. The role of SPARC as a biomarker was also studied (as discussed previously). ${ }^{55}$

Overall, of the 67 patients recruited, 20, 44, and three patients received nab-paclitaxel at 100,125 , and $150 \mathrm{mg} / \mathrm{m}^{2}$, respectively, and the maximum tolerated dose was $1,000 \mathrm{mg} / \mathrm{m}^{2}$ of gemcitabine and $125 \mathrm{mg} / \mathrm{m}^{2}$ of nab-paclitaxel once weekly for 3 weeks every 28 days. Subsequently, 44 patients were treated at the maximum tolerated dose; median PFS was 7.9 months (95\% CI 5.8-11) and median OS was 12.2 months (95\% CI 8.9-17.9). The ORR was $46 \%$ for all 67 patients and $48 \%$ for those treated at the maximum tolerated dose, with a one-year survival rate of $48 \%$. Positron emission tomography scan results revealed a median decrease in metabolic activity of $79 \%$, and patients with a complete metabolic response had a significantly improved OS compared with those who did not (median 20.1 versus 10.3 months, $P=0.01$ ). CA19-9 levels decreased rapidly, with a median time to maximum decrease of 89 days and a median maximum change of $91 \%$. Patients with a greater than 50\% decline in CA19-9 levels had better median OS (13.6 versus 6.5 months), PFS (8 versus 3.6 months), and ORR (62\% versus 33\%), compared with patients with a less than $50 \%$ decline. ${ }^{55}$ 
Treatment with this regimen was also well tolerated, with the majority of treatment-related adverse effects being grade 1 or 2 in severity. Sepsis and neutropenia were the major dose-limiting toxicities. At the maximum tolerated dose, the most commonly encountered grade 3 or higher adverse effects were fatigue (27\%) and neuropathy (20\%). Of the grade 3 or higher treatment-related hematological toxicities, neutropenia (67\%), leukopenia (44\%), and thrombocytopenia $(23 \%)$ were the most common. This study was unique because of the multifaceted assessment of tumor response using positron emission tomography scans in addition to conventional methods and analysis of biomarkers. The ORR, PFS, and OS realized with this combination regimen proved to be the highest among any of the reported Phase II trials in patients with PDA, and led to significant optimism to further validate the results in a Phase III trial (discussed in the "Phase III" section).

Zhang et al reported the results of a Phase I/II study among Chinese patients with advanced PDA treated with nab-paclitaxel at 80,100 , or $120 \mathrm{mg} / \mathrm{m}^{2}$, in combination with gemcitabine at $1,000 \mathrm{mg} / \mathrm{m}^{2}$ on days 1 and 8 , repeated every 21 days. ${ }^{65}$ Of the 21 patients enrolled in this study, the maximum tolerated dose of nab-paclitaxel was established at $120 \mathrm{mg} / \mathrm{m}^{2}{ }^{25}$ Elevated alanine aminotransferase and febrile neutropenia were the dose-limiting toxicities, and the safety profile was favorable. The ORR (42\%) and OS (12.7 months) were consistent with the results reported in the aforementioned Phase I/II study by Von Hoff et al. ${ }^{55}$ The addition of capecitabine to the combination of nab-paclitaxel and gemcitabine was also studied in a Phase I trial by Ko et al. ${ }^{66}$ Chemotherapy treatment cycles were 14 days long, with capecitabine given on days 1-7 and both gemcitabine and nab-paclitaxel given on day 4 . From the 14 patients in this study, the maximum tolerated dose of paclitaxel was established at $100 \mathrm{mg} / \mathrm{m}^{2}$ intravenously, gemcitabine $750 \mathrm{mg} / \mathrm{m}^{2}$ intravenously, and capecitabine $750 \mathrm{mg} / \mathrm{m}^{2}$ orally twice daily. Although the regimen was well tolerated, the ORR (14\%), OS (7.5 months), and PFS (4.5 months) were markedly lower compared with other studies. Although the authors explained these marginal results owing to suboptimal dosing of each separate drug component in the regimen at maximum tolerated dose, ${ }^{66}$ the small sample size is a limiting factor in drawing conclusions from this trial.

In another Phase I study, patients with metastatic pancreatic cancer were stratified into two cohorts and received nabpaclitaxel at a fixed dose of either $100 \mathrm{mg} / \mathrm{m}^{2}$ intravenously weekly for 3 weeks every 28 days or $260 \mathrm{mg} / \mathrm{m}^{2}$ every 3 weeks in combination with three escalating doses $(100 \mathrm{mg}, 200 \mathrm{mg}$, or
$300 \mathrm{mg}$ per day) of the oral vascular endothelial growth factor receptor/RET/epidermal growth factor receptor antagonist, vandetanib. ${ }^{67}$ One dose-limiting toxicity at each dose level of vandetanib was observed in the weekly nab-paclitaxel cohort, while no dose-limiting toxicities were seen in the second cohort. Of the 29 patients who were treated, 22 were evaluable, and six $(27.5 \%)$ had a partial response, ten $(45 \%)$ had stable disease, and six (27.5\%) had progressive disease. The median PFS and OS were 5.3 months (95\% CI 3.7-7.3) and 8.2 months (95\% CI 6.2-11.5), respectively. The maximum tolerated dose in both cohorts was the maximum planned dose of vandetanib. Treatment was well tolerated in both cohorts. ${ }^{67}$

\section{Phase III}

MPACT was a Phase III, open-label international study that enrolled patients with metastatic pancreatic cancer at 151 centers in eleven countries. ${ }^{68}$ Eligible patients were randomized to receive nab-paclitaxel $\left(125 \mathrm{mg} / \mathrm{m}^{2}\right)$ followed by gemcitabine $\left(1,000 \mathrm{mg} / \mathrm{m}^{2}\right)$ on days 1,8 , and 15 every 4 weeks or monotherapy with gemcitabine $\left(1,000 \mathrm{mg} / \mathrm{m}^{2}\right)$ weekly for 7 of 8 weeks for the first cycle and then on days 1,8 , and 15 every 4 weeks from the second cycle onwards. Patients were assessed for response every 8 weeks with computed tomography scans or magnetic resonance imaging along with serial measurements of CA19-9. In the intention to treat population, the primary end point of median OS was 8.5 months with nab-paclitaxel plus gemcitabine as compared with 6.7 months with gemcitabine monotherapy (HR for death $0.72 ; 95 \%$ CI $0.62-0.83, P<0.001$ ). The secondary end point of median PFS was 5.5 months in the combination chemotherapy arm versus 3.7 months in the monotherapy arm (HR for disease progression or death $0.69 ; 95 \%$ CI $0.58-0.82, P<0.001)$. The ORR was also significantly better $(23 \%$ versus $7 \%, P<0.001)$ in favor of nab-paclitaxel and gemcitabine.

Grade 3 or higher neutropenia was more common with the combination of two agents than with gemcitabine alone $(38 \%$ versus $27 \%$ ), and necessitated growth factor support more frequently ( $26 \%$ versus $15 \%$ ). Although grade 3 or higher neuropathy was more common with the doublet (17\% versus $1 \%$ ), it was rapidly reversible when nab-paclitaxel was interrupted, with a median time to resolution of 29 days and was seldom responsible for discontinuation of nab-paclitaxel (8\%). Grade 3 or higher fatigue was also more common with the combination $(17 \%$ versus $7 \%)$, as was sepsis $(5 \%$ versus $2 \%)$ and pneumonitis ( $4 \%$ versus $1 \%$ ), although fatalities amounted to $4 \%$ in both groups. Adherence to treatment and dose intensity were high with both agents, and the median cumulative dose 
Table 4 Comparison of results from the MPACT and FOLFIRINOX trials

\begin{tabular}{lllll}
\hline Study (n) & $\begin{array}{l}\text { Median OS } \\
\text { months }\end{array}$ & $\begin{array}{l}\text { Median PFS } \\
\text { months }\end{array}$ & ORR & $\begin{array}{l}\text { One-year } \\
\text { survival }\end{array}$ \\
\hline $\begin{array}{l}\text { Gemcitabine* } \\
(n=430)\end{array}$ & 6.7 & 3.7 & $7 \%$ & $22 \%$ \\
$\begin{array}{l}\text { Nab-paclitaxel }+ \\
\text { gemcitabine }(n=43 \mathrm{I})\end{array}$ & 8.5 & 5.5 & $23 \%$ & $35 \%$ \\
$\begin{array}{l}\text { FOLFIRINOX } \\
(\mathrm{n}=342)\end{array}$ & 12.2 & 6.4 & $31.6 \%$ & $48.4 \%$ \\
\hline
\end{tabular}

Notes: *Gemcitabine control cohort from MPACT trial (results comparable with FOLFIRINOX control group).

Abbreviations: FOLFIRINOX, 5-fluorouracil, leucovorin, irinotecan, oxaliplatin; OS, overall survival; PFS, progression-free survival; ORR, overall response rate.

of gemcitabine administered was higher in the combination treatment arm, reflecting the increased duration of treatment in this group.

The MPACT trial has several positive attributes, such as multinational enrollment, evaluation of OS as a primary endpoint as compared with PFS, and inclusion of patients with poor performance status ( $8 \%$ ) and advanced age (10\%), all of which greatly increase the applicability of the trial's results to a wider range of patients with advanced PDA. Minor limitations of the study include a nonclassical dose modification schedule and lack of quality of life measurement. Its favorable toxicity profile and convenience due to a weekly dosing schedule without requirement of home infusion pumps also make this combination regimen more attractive as a palliative treatment option (see Table 4 for comparison of results from the MPACT and FOLFIRINOX trials). The combination of improved response rate and OS makes utilization of this combination therapy attractive for implementation in earlier disease settings, such as neoadjuvant, unresectable locally advanced disease, and as adjuvant therapy (Table 5). The role of this combination as well as FOLFIRINOX in an earlier disease setting is currently under investigation, and the results of these clinical trials are yet to be reported. The toxicity profile of the combination of gemcitabine and nab-paclitaxel also allows this combination to serve as a cytotoxic chemotherapy backbone for the addition of molecular targeted therapies. Many such clinical trials are ongoing or in development. ${ }^{69}$

Table 5 Ongoing clinical trials involving nab-paclitaxel in the treatment of non-metastatic PDA, stratified by treatment setting (according to http://www.clinicaltrials.gov, accessed September 20I4)

\begin{tabular}{|c|c|c|c|c|c|}
\hline $\begin{array}{l}\text { Clinical trial } \\
\text { identifier }\end{array}$ & Setting & Medications studied & Phase & Status & $\begin{array}{l}\text { Estimated } \\
\text { completion date }\end{array}$ \\
\hline NCTOI43I 794 & $\begin{array}{l}\text { Neoadjuvant; borderline } \\
\text { resectable }\end{array}$ & nab-Pac + Gem + LDE-225 & $\mathrm{I} / \mathrm{II}$ & Recruiting & September 2016 \\
\hline NCT022I0559 & $\begin{array}{l}\text { Neoadjuvant; locally advanced, } \\
\text { unresectable }\end{array}$ & nab-Pac + Gem \pm FG-3019 & II & Recruiting & July 2016 \\
\hline NCT02I25I36 & Neoadjuvant; locally advanced & nab-Pac + Gem versus FOFIRINOX & II & Not yet recruiting & December 2017 \\
\hline NCT0I4704I7 & Neoadjuvant & $\begin{array}{l}\text { nab-Pac }+ \text { Gem versus nab-Pac }+ \\
\text { Gem }+ \text { radiotherapy }\end{array}$ & II & Ongoing, not recruiting & January 2014 \\
\hline NCTOI 726582 & Neoadjuvant & nab-Pac + Gem versus other* & II & Recruiting & June 2015 \\
\hline NCTOI $29801 \mathrm{I}$ & Neoadjuvant & nab-Pac + Gem & II & Ongoing, not recruiting & December 2013 \\
\hline NCT020475I3 & $\begin{array}{l}\text { Neoadjuvant + adjuvant versus } \\
\text { adjuvant only; resectable }\end{array}$ & nab-Pac + Gem & II & Not yet recruiting & March 2019 \\
\hline NCT0I978I84 & $\begin{array}{l}\text { Neoadjuvant, potentially } \\
\text { resectable }\end{array}$ & nab-Pac + Gem \pm hydroxychloroquine & II & Recruiting & November 2017 \\
\hline NCT02243007 & Neoadjuvant & nab-Pac + Gem versus FOLFIRINOX & II & Not yet recruiting & July 2018 \\
\hline NCT0I964430 & Adjuvant & nab-Pac + Gem versus Gem & III & Recruiting & April 2019 \\
\hline NCT0202302I & Adjuvant & nab-Pac + Gem & II & Recruiting & May 2017 \\
\hline NCT02043730 & Locally advanced, unresectable & nab-Pac + Gem versus Gem alone & II & Ongoing, not recruiting & January 2017 \\
\hline NCT0I8448I7 & Metastatic & nab-Pac + Gem \pm OGX-427 & II & Recruiting & May 2016 \\
\hline NCT0I839487 & $\begin{array}{l}\text { Metastatic, previously } \\
\text { untreated }\end{array}$ & $\begin{array}{l}\text { nab-Pac }+ \text { Gem }+ \text { PEGPH20 versus } \\
\text { nab-Pac }+ \text { Gem }\end{array}$ & II & Recruiting & April 2016 \\
\hline NCT0I834235 & $\begin{array}{l}\text { Metastatic, locally advanced, } \\
\text { or unresectable }\end{array}$ & nab-Pac + Gem \pm NPC-IC & I, II & Recruiting & October 2015 \\
\hline NCT0I46I9I5 & Metastatic & $\mathrm{nab}-\mathrm{Pac}+\mathrm{Gem} \pm \mathrm{ODSH}$ & II & Recruiting & March 2013 \\
\hline NCT02I0102I & Metastatic, first line & nab-Pac + Gem + momelotinib & II & Recruiting & September 2016 \\
\hline
\end{tabular}

Notes: *Treatment regimen to be chosen based on molecular profiling. LDE-225 is a Hedgehog inhibitor; FG-30I9 is an anti-fibrotic antibody; and NPC-IC is a chimeric monoclonal antibody.

Abbreviations: nab-Pac, nab-paclitaxel; Gem, gemcitabine; FOLFIRINOX, 5-fluorouracil, leucovorin, irinotecan, oxaliplatin; ODSH, 2-0, 3-0 desulfated heparin. 


\section{Conclusion}

In this era of improved outcomes with molecularly targeted antineoplastic therapy, PDA had remained an obstinate exception due to the lack of clearly identified targetable oncogenic pathways. However, through better understanding of tumor biology, it has become possible to devise methods to improve drug delivery to a complex tumor microenvironment as in the case of PDA. The development of nab-paclitaxel and its success in the treatment of metastatic PDA is a prime example of the interface between concepts of nanotechnology and the ingenious principles of drug development to target this recalcitrant disease by exploiting the tumor's own biological properties, such as its desmoplastic stroma, macropinocytosis, and reliance on albumin for it metabolic needs. The combination of nab-paclitaxel and gemcitabine has emerged as a new paradigm in the management of metastatic PDA.

\section{Disclosure}

CDW has received clinical research support and honoraria, Celgene Inc. VN has no conflicts of interest to report.

\section{References}

1. Siegel R, Ma J, Zou Z, Jemal A. Cancer Statistics, 2014. CA Cancer J Clin. 2014;64:9-29.

2. Malvezzi M, Bertuccio P, Levi F, La Vecchia C, Negri E. European cancer mortality predictions for the year 2014. Ann Oncol. 2014;25: 1650-1656.

3. Carpelan-Holmstrom M, Nordling S, Pukkala E, et al. Does anyone survive pancreatic ductal adenocarcinoma? A nationwide study reevaluating the data of the Finnish Cancer Registry. Gut. 2005;54: 385-387.

4. Jemal A, Bray F, Center MM, Ferlay J, Ward E, Forman D. Global Cancer Statistics. CA Cancer J Clin. 2011;61:69-90.

5. Rahib L, Smith BD, Aizenberg R, Rosenzweig AB, Fleshman JM, Matrisian LM. Projecting cancer incidence and deaths to 2030: the unexpected burden of thyroid, liver and pancreas cancers in the United States. Cancer Res. 2014;74:2913-2921.

6. Feig C, Gopinathan A, Neesse A, Chan DS, Cook N, Tuveson DA. The pancreas cancer microenvironment. Clin Cancer Res. 2012;18: 4266-4276.

7. Mahadevan D, Von Hoff DD. Tumor stroma interactions in pancreatic ductal adenocarcinoma. Mol Cancer Ther. 2007;6:1186-1197.

8. Jones S, Zhang X, Parsons DW, et al. Core signaling pathways in human pancreatic cancers revealed by global genomic analyses. Science. 2008;321:1801-1806.

9. Yeo CJ, Cameron JL, Lillemore KD, et al. Pancreaticoduodenectomy for cancer of the head of the pancreas: 201 patients. Ann Surg. 1995;221: 721-731.

10. Shaib Y, Davilla J, Naumann C, El-Serag H. The impact of curative intent surgery on the survival of pancreatic cancer patients: a US population-based study. Am J Gasteroenterol. 2007;102: 1377-1382.

11. Raimondi S, Maisonneuve P, Lowenfels AB. Epidemiology of pancreatic cancer: an overview. Nat Rev Gasteroenterol Hepatol. 2009;6:699-708.

12. Hidalgo M. Pancreatic cancer. N Engl J Med. 2010;362:1605-1617.

13. Li D, Xie K, Wolff R, Abbruzzese JL. Pancreatic cancer. Lancet. 2004;363:1049-1057.
14. Burris HA III, Moore MJ, Andresen J, et al. Improvements in survival and clinical benefit with gemcitabine as first-line therapy for patients with advanced pancreas cancer: a randomized trial. J Clin Oncol. 1997; 15:2403-2413.

15. Colucci G, Giuliani F, Gebbia V, et al. Gemcitabine alone or with cisplatin for the treatment of patients with locally advanced and/or metastatic pancreatic carcinoma: a prospective, randomized phase III study of the Gruppo Oncologia dell'Italia Meridionale. Cancer. 2002;94: 902-910.

16. Cunningham D, Chau I, Stocken DD, et al. Phase III randomized comparison of gemcitabine versus gemcitabine plus capecitabine in patients with advanced pancreatic cancer. J Clin Oncol. 2009;27: 5513-5518.

17. Louvet C, Labianca R, Hammel P, et al. Gemcitabine in combination with oxaliplatin compared with gemcitabine alone in locally advanced or metastatic pancreatic cancer: results of a GERCOR and GISCAD phase III trial. J Clin Oncol. 2005;23:3509-3516.

18. Oettle H, Richards D, Ramanathan RK, et al. A phase III trial of pemetrexed plus gemcitabine versus gemcitabine in patients with unresectable or metastatic pancreatic cancer. Ann Oncol. 2005;16:1639-1645.

19. Rocha Lima CM, Green MR, Rotche R, et al. Irinotecan plus gemcitabine results in no survival advantage compared with gemcitabine monotherapy in patients with locally advanced or metastatic pancreatic cancer despite increased tumor response rate. J Clin Oncol. 2004;22: 3776-3783.

20. Moore MJ, Goldstein D, Hamm J, et al. Erlotinib plus gemcitabine compared with gemcitabine alone in patients with advanced pancreatic cancer: a phase III trial of the National Cancer Institute of Canada Clinical Trials Group. J Clin Oncol. 2007;25:1960-1966.

21. Conroy T, Desseigne F, Ychou M, et al. FOLFIRINOX versus gemcitabine for metastatic pancreatic cancer. $N$ Engl J Med. 2011;364: 1817-1825.

22. Provenzano PP, Cuevas C, Chang AE, Goel VK, Von Hoff DD, Hingorani SR. Enzymatic targeting of the stroma ablates physical barriers to treatment of pancreatic ductal adenocarcinoma. Cancer Cell. 2012;21:418-429.

23. Olive KP, Jacobetz MA, Davidson CJ, et al. Inhibition of hedgehog signaling enhances delivery of chemotherapy in a mouse model of pancreatic cancer. Science. 2009;324:1457-1461.

24. Hidalgo M, Maitra A. The hedgehog pathway and pancreatic cancer. N Engl J Med. 2009;361:2094-2096.

25. Wani MC, Horwitz SB. Nature as a remarkable chemist: a personal story of the discovery and development of Taxol. Anticancer Drugs. 2014;25:482-487.

26. Horwitz B. Mechanism of action of Taxol. Trends Pharmacol Sci. 1992;13:134-136.

27. Picard M, Castells MC. Re-visiting hypersensitivity reactions to taxanes: a comprehensive review. Clin Rev Allerg Immunol. April 17, 2014. [Epub ahead of print.]

28. Weiss RB, Donehower RC, Wiernik PH, et al. Hypersensitivity reactions from Taxol. J Clin Oncol. 1990;8:1263-1268.

29. Cucinotto I, Fiorillo L, Gualtieri S, et al. Nanoparticle albumin bound paclitaxel in the treatment of human cancer: nanodelivery reaches prime-time? J Drug Deliv. 2013;2013:905091.

30. Sparreboom A, van Zuylen L, Brouwer E, et al. Cremaphor EL mediated alteration of paclitaxel distribution in human blood: clinical pharmacokinetic implications. Cancer Res. 1999;59:1454-1457.

31. Van Tellingen O, Huizing MT, Panday VR, et al. Cremaphor EL causes (pseudo-) non-linear pharmacokinetics of paclitaxel in patients. $\mathrm{Br} J$ Cancer. 1999;81:330-335.

32. Gelderblom H, Verweij J, Nooter K, Sparreboom A. Cremaphor EL: the drawbacks and advantages of vehicle selection for drug formulation. Eur J Cancer. 2001;37:1590-1598.

33. Whitehead RP, Jacobson J, Brown TD, Taylor SA, Weiss GR, Macdonald JS. Phase II trial of paclitaxel and granulocyte colonystimulating factor in patients with pancreatic carcinoma: a Southwest Oncology Group study. J Clin Oncol. 1997;15:2414-2419. 
34. Lam AP, Sparano JA, Vinciguerra, et al. Phase II study of paclitaxel plus the protein kinase $\mathrm{C}$ inhibitor bryostatin-1 in advanced pancreatic carcinoma. Am J Clin Oncol. 2010;33:121-124.

35. Maeda S, Motoi F, Onogawa T, et al. Paclitaxel as second-line chemotherapy in patients with gemcitabine-refractory pancreatic cancer: a retrospective study. Int J Clin Oncol. 2011;16:539-545.

36. Kim YJ, Bang S, Park JY, Park SW, Chung JB, Song SY. Phase II study of 5-fluorouracil and paclitaxel in patients with gemcitabine-refractory pancreatic cancer. Cancer Chemother Pharmacol. 2009;63:529-533.

37. Ryan DP, Kulke MH, Fuchs CS, et al. A Phase II study of gemcitabine and docetaxel in patients with metastatic pancreatic carcinoma. Cancer. 2002;94:97-103.

38. Stathopoulos GP, Mavroudis D, Tsavaris N, et al. Treatment of pancreatic cancer with a combination of docetaxel, gemcitabine and granulocyte colony-stimulating factor: a phase II study of the Greek Cooperative Group for Pancreatic Cancer. Ann Oncol. 2001;12:101-103.

39. Cascinu S, Gasparini G, Catalano V, et al. A phase I-II study of gemcitabine and docetaxel in advanced pancreatic cancer: a report from the Italian Group for the Study of Digestive Tract Cancer (GISCAD) Ann Oncol. 1999;10:1377-1379.

40. Desai N. Challenges in development of nanoparticle-based therapeutics. AAPS J. 2012;14:282-295.

41. Ibrahim NK, Desai N, Legha S, et al. Phase I and pharmacokinetic study of ABI-007, a Cremophor-free, protein-stabilized, nanoparticle formulation of paclitaxel. Clin Cancer Res. 2002;8:1038-1044.

42. Highlights of prescribing information: Abraxane (package insert) 2013. Available from: http://www.abraxane.com/downloads/ Abraxane_PrescribingInformation.pdf. Accessed October 19, 2014.

43. Paal K, Muller J, Hegedus L. High affinity binding of paclitaxel to human serum albumin. Eur J Biochem. 2001;268:2187-2191.

44. Gradishar WJ. Albumin-bound paclitaxel: a next generation taxane. Expert Opin Pharmacother. 2006;7:1041-1053.

45. John TA, Vogel SM, Tiruppathi C, Malik AB, Marshall RD. Quantitative analysis of albumin uptake and transport in the rat microvessel endothelial monolayer. Am J Physiol Lung Cell Mol Physiol. 2003;284:L187-L196.

46. Chen T, Liu L, Xu H-X, et al. Significance of caveolin-1 regulators in pancreatic cancer. Asian Pac J Cancer Prev. 2013;14:4501-4507.

47. Schubert W, Frank PG, Razani B, Park DS, Chow CW, Lisanti MP. Caveolae-deficient endothelial cells show defects in the uptake and transport of albumin in-vivo. J Biol Chem. 2001;276:8619-8622.

48. Desai N, Trieu V, Yao Z, et al. Increased antitumor activity, intratumor paclitaxel concentrations, and endothelial cell transport of Cremophorfree, albumin bound paclitaxel, ABI-007, compared with Cremophorbased paclitaxel. Clin Cancer Res. 2006;12:1317-1324.

49. Surapaneni MS, Das SK, Das NG. Designing paclitaxel delivery systems aimed at improved patient outcomes: current status and challenges. ISRN Pharmacol. 2012;2012:623139.

50. Commisso C, Davidson SM, Soydaner-Azeloglu RG, et al. Macropinocytosis of protein is an amino acid supply route in Ras-transformed cells. Nature. 2013;497:633-637.

51. Sato N, Fukushima N, Maehara N, et al. SPARC/osteonectin is a frequent target for aberrant methylation in pancreatic adenocarcinoma and a mediator of tumor-stromal interactions. Oncogene. 2003;22: 5021-5030.
52. Kalluri R, Zeisberg M. Fibroblasts in cancer. Nat Rev Cancer. 2006;6: $392-401$.

53. Infante JR, Matsubayashi $\mathrm{H}$, Sato N, et al. Peritumoral fibroblast SPARC expression and patient outcome with resectable pancreatic adenocarcinoma. J Clin Oncol. 2007;25:319-325.

54. Ryu B, Jones J, Hollingsworth MA, et al. Invasion specific genes in malignancy: serial analysis of gene expression comparisons of primary and passaged cancers. Cancer Res. 2001;61:1833-1838.

55. Von Hoff DD, Ramanathan RK, Borad MJ, et al. Gemcitabine plus nab-paclitaxel is an active regimen in patients with advanced pancreatic cancer: a phase I/II trial. J Clin Oncol. 2011;29:4548-4554.

56. Neesse A, Frese KK, Chan DS, et al. SPARC independent drug delivery and antitumor effects of nab-paclitaxel in genetically engineered mice. Gut. 2014;63:974-983.

57. Hidalgo M, Piaza C, Llei, et al. SPARC analysis in the phase III MPACT trial of nab-paclitaxel plus gemcitabine vs gemcitabine alone for patients with metastatic pancreatic cancer. Ann Oncol. 2014;25 Suppl 2:ii106.

58. Alvarez R, Musteanu M, Garcia-Garcia E, et al. Stromal disrupting effects of nab-paclitaxel in pancreatic cancer. Br J Cancer. 2013;109:926-933.

59. Sousa CM, Kimmelman AC. The complex landscape of pancreatic cancer metabolism. Carcinogenesis. 2014;35:1441-1450.

60. Lohr M, Kloppel G, Maisonneuve P, Lowenfels AB, Luttges J. Frequency of K-ras mutations in pancreatic intraductal neoplasias associated with pancreatic ductal adenocarcinoma and chronic pancreatitis: a metaanalysis. Neoplasia. 2005; 7:17-23.

61. Bryant KL, Mancias JD, Kimmelman AC, Der CJ. KRAS: feeding pancreatic cancer proliferation. Trends Biochem Sci. 2014;39:91-100.

62. Lim JP, Gleeson PA. Macropinocytosis: an endocytic pathway for internalising large gulps. Immunol Cell Biol. 2011;89:836-843.

63. Neesse A, Michl P, Tuveson DA, Ellenreider V. nab-Paclitaxel: novel clinical and experimental evidence in pancreatic cancer. $Z$ Gastroenterol. 2014;52:360-366.

64. Frese KK, Neesse A, Cook N, et al. nab-Paclitaxel potentiates gemcitabine activity by reducing cytidine deaminase levels in a mouse model of pancreatic cancer. Cancer Discov. 2012;2:260-269.

65. Zhang DS, Wang DS, Wang ZQ, et al. Phase I/II study of albumin bound nab-paclitaxel plus gemcitabine administered to Chinese patients with advanced pancreatic cancer. Cancer Chemother Pharmacol. 2013;71:1065-1072.

66. Ko AH, Truong TG, Kantoff E, et al. A phase I trial of nab-paclitaxel, gemcitabine and capecitabine for metastatic pancreatic cancer. Cancer Chemother Pharmacol. 2012;70:875-881.

67. El-Khoueiry AB, Iqbal S, Lenz H, et al. A phase I study of two different schedules of nab-paclitaxel with ascending doses of vandetanib with expansion in patients with pancreatic cancer. J Clin Oncol. 2011; 29 Suppl:Abstr 4124.

68. Von Hoff DD, Ervin T, Arena FP, et al. Increased survival in pancreatic cancer with nab-paclitaxel plus gemcitabine. N Engl J Med. 2013;369: 1691-1703.

69. Fontana E, Sclafani F, Cunningham D. Emerging treatments for advanced pancreatic cancer: clinical potential of albumin-bound paclitaxel. Gastrointestinal Cancer: Targets and Therapy. 2014;4:89-101.
Gastrointestinal Cancer: Targets and Therapy

\section{Publish your work in this journal}

Gastrointestinal Cancer: Targets and Therapy is an international, peer-reviewed, open access journal focusing on gastro-intestinal cancer research, identification of therapeutic targets and the optimal use of preventative and integrated treatment interventions to achieve improved outcomes, enhanced survival and quality of life for the

\section{Dovepress}

cancer patient. The manuscript management system is completely online and includes a very quick and fair peer-review system. Visit http://www.dovepress.com/testimonials.php to read real quotes from published authors. 